\title{
MODELING AND CALIBRATING CAPACITY OF LARGE ROUNDABOUTS
}

\author{
HASHIM M.N. AL-MADANI ${ }^{1} \&$ ANTONIO PRATELLI ${ }^{2}$ \\ ${ }^{1}$ Department of Civil Engineering \& Architecture, University of Bahrain, Bahrain. \\ ${ }^{2}$ Department of Civil Engineering, Pissa University, Italy.
}

\begin{abstract}
Roundabout models, available in the literature widely, vary between one method and another. Majority of the models are solely based on circulating flow to estimate capacity. The relationship between maximum entry flow of large dual and triple lane roundabouts and their geometric and traffic characteristics is investigated here for saturated flow condition using multivariate analysis. The developed model, based on the data gathered from 13 roundabouts in Bahrain, matched the field data reasonably well. The significant predictors, out of 60 tested ones, included circulating and exiting flows, number of entry and circulating lanes, circulating and entry widths, inscribed diameter and flare length. Capacities predicted through various international models varied considerably with both the developed model and the field data. The international models were then calibrated against the model, and consequently the field data, so as to have significant match with the two. The procedure followed in developing the model and calibrating the international models consisted of eight stages. It involved identification of significant correlation of individual predictor with capacity, multivariate regression analysis, model smoothing, multi-collinearity test, redevelopment of the model after adjusting the variables causing collinearity, comparison analysis with seven known international models and calibration of the international model. While UK, aaSIDRA and French models required around 50\% reduction to match the developed model and actual data; US FHWA and Swiss models required 25\% reduction and US HCM and German models required just $8 \%$ adjustments. Such clear variations call for further research. The findings assist the urban planners as when to shift from one type of intersection control into another involving roundabout, and vice versa.

Keywords: Adjustment factor, calibration, circulating flow, exiting flow, maximum entry flow, roundabout capacity.
\end{abstract}

\section{INTRODUCTION}

Nowadays roundabouts are spreading widely in many countries because of their advantages over other types of intersection control. The main principle reason is the profit of safety over other cross roads [1-3]. Some of the other advantages include minimum maintenance cost and nice landscape. However, they also carry several serious disadvantages, many of which are usually overlooked [4]. Internationally, the experience with traffic circles was unsuccessful, with many countries experiencing locking up of circles as traffic volumes increased [5]. As a result, a mandatory "Give-way" rule at all the circular intersection was adopted in UK to prevent locking up. Wardrop developed some models related to roundabout capacity in 1957. Al-Madani [4] found that roundabouts perform better than traffic signals, delay wise, when the traffic demand is low. However, as the demand increases at a roundabout so do the queue length and the delays. Besides drivers' frustration due to the unpredictable delays at congested roundabouts, when compared with traffic signals, long queues are inevitable. Such phenomena lead Governments of Bahrain and Qatar to convert most of the major roundabouts on the main roads into traffic signals. Some were constructed during the '60s. Akçelik [6] also observed that roundabout performs well at low to medium flow conditions. Clear capacity reduction was observed at high demand levels.

\section{ROUNDABOUT CAPACITY}

Roundabout capacity is the main determinant performance measure for the prediction of delay, queue length, traffic assignments, gating strategies and several other important parameters. Capacity 
is the maximum sustainable entry flow rate that an approach can accommodate during a specific period under prevailing traffic, geometric and control conditions. It is different than maximum flow that an intersection can handle [7], which is the practical capacity under high demand volume, not under prevailing conditions. Hollis et al. [8] and Tenekci et al. [9] defined capacity as the maximum entering flow when the flow is sufficient to cause continuous and persistent queuing. On the other hand, service flow rate, as defined in Highway Capacity Manual-2010 [10], is the maximum directional rate of flow that can be sustained in a given segment under prevailing roadway, traffic and control conditions. Most of the capacity models are either analytical ones based on gap acceptance, with no actual observations other than headways, or empirical regression ones based on observed geometric and flow parameters. The former follows probabilistic approach and the latter follows deterministic one. It is unusual to have a mix of the two, since randomness nature of traffic movement will diminish at near or beyond saturation conditions. The drivers are forced to follow those ahead of them. Russell and Rys [11] also questioned the validity of gap acceptance models at near capacity conditions. Inconsistent gap acceptance occurs, which has not been accounted for in theory, when drivers reject large gaps or make force entry during congestion, or when other drivers give up their right of way [12]. Furthermore, evaluation of the critical headway is difficult [12], as for example different vehicle types accepting different gaps. Empirical models showed poor transferability to other countries or other times [12] without being calibrated. Kimber [13] stated that capacity estimates based on gap acceptance models are not suitable for the application in England. This was due to the problems related to human behavior. On the other hand, Fisk [14] found regression models to be difficult for frequent application due to large number of data requirements. Micro-simulation techniques are lately used by some researchers. Such techniques typically simulate traffic system on a vehicle-by-vehicle basis by updating vehicles' position, speed and other variables on small time steps as one second interval or less [15]. Stanek and Milan [16] recommended us to use macroscopic methods, such as FHWA, RODEL and aaSIDRA for the general use of capacity during unsaturated conditions. For oversaturated conditions, microscopic methods such as Paramics and VISSIM are preferred. However, they involved very limited tested roundabouts and utilized only RODEL and aaSIDRA models for comparison purposes.

The maximum flow rate that can be accommodated at a roundabout entry depends mainly on the circulating flow around the roundabout that conflicts with the entry flow, exiting flow and the geometric elements of the roundabout. The most important geometric elements are the width of the entry, the width of the circulatory way, or number of lanes around the central island. Wider circulatory roadways allow vehicles to travel alongside, or follow, each other in tighter bunches and so provide longer gaps between bunches of vehicles. The flare length also affects the capacity. The inscribed circle diameter and the entry angle have minor effects on capacity. In fact, TRL invented mini roundabouts which performed better than some larger ones in terms of capacities [17].

There are several analytical and empirical models for the entry flow estimations. Some are very well known and others are less popular. However, capacities estimated through these models widely differ from one model to another [18]. Some are very simple requiring minimum data entry as the US Highway Capacity Manual (HCM-2010) and the Federal Highway Administration (FHWA) models. Others are much more complicated requiring extensive data gathering and calculations as UK RODEL, Australian aaSIDRA, French GIRABASE and Indian models. The UK and the Australian aaSIDRA models are the most famous ones. The question of how good the capacity estimate of each model is, when compared with actual data, requires careful investigation. Pratelli [19] found clear differences in capacity estimates when French and Swiss models were compared with actual data in Italy. Overestimation of $25 \%$ to $79 \%$ was observed in the capacity. The need for capacity evaluation of various models and software programs, available worldwide, was stressed by 
Jacquemart [20]. Unlike traffic signals, roundabouts lack unified capacity models. Several capacity models are currently available. The dominant variable in all these models is the circulating flow.

Most of capacity models are developed in Europe and Australia. There are several models currently used by both the researchers and the operators. The UK model, RODEL [21], is based on the work carried out by Kimber and Hollis [22] and Kimber [17] for TRL. It requires measurement of extensive geometric parameters. Many researchers, such as Robinson and Rodegerdts [23] and HCM [10], simplified the earlier model for specific geometric constants, since the model is quite complicated [23]. The UK model overestimated the roundabout capacity for critical lane in the USA [24, 25].

The Australian aaSIDRA capacity method was improved by Akçelik $[6,26]$ and incorporated in a widely known software called aaSIDRA [7]. The method employs several traffic and few geometric parameters. The Australian model- NAASRA was developed by National Association of Australian State Road Authorities [27-29]. The model mainly depends on the circulating flow. The German model is derived from the Tanner-Wu capacity equation and has been introduced officially into the German Highway Capacity Manual in 2001 [30, 31]. The detailed formula for the entry flow is discussed by $\mathrm{Wu}[32,33]$. The French model is based on the work carried out by Louah (1992) which later was incorporated into a model known as GIRABASE [34]. The model is among the very limited models that incorporates exiting flow, besides circulating flow, in estimation of entry flow. The French model over-predicted the entry capacity when tested on the American roundabouts [24].

There are at least two models currently available in the recent US literature. The first is available in the Highway Capacity Manual 2010 [10]. The second is a simplified version of the British linear regression model and is cited in the Federal Highway Administration (FHWA) Roundabout Guidebook [24, 35]. According to Robinson and Rodegerdts [23] the FHWA model is based on Wu's model $[32,33]$. The basic concept of the Indian Model is drawn from Wardrop late '50s' literature $[36,37]$. Bahrain models [38] involve exponential and logarithmic terms for different number of entry and circulating lanes. The models incorporate only circulating flow to estimate the capacity.

The earlier capacity models widely vary in their capacity estimates, input requirements, accuracy of measured geometric data, assumptions made in model derivation, techniques used in the development of the models and level of saturation of the gathered data. With the exception of Bahrain model all the earlier models are designed for the general use of flow conditions. In fact, high variations between the various models were observed during saturated conditions [38]. Better accuracy of entry flows during high demand flows is highly crucial for better administration of traffic and selection of traffic control system at intersections. It is also worth mentioning that while measurement of capacities at signalized intersections is quite unique and well-set considering the various methods, as in the Highway Capacity Manual 2010 [10], it is not for roundabouts. Robinson and Rodegerdts [23] concluded that further research in the field of roundabout capacity should be conducted. None of the earlier studies quantified the reduction in the roundabout capacity due to wet surface or environmental effect [9]. The aaSIDRA method considers calibration of the model to reflect environmental effect, though no calculation was presented by the developers [9, 7]. In Leeds (UK) Tenekeci et al. [9]. estimated a reduction of $17 \%$ in the roundabout capacity under wet-light condition and of $25 \%$ under wet-dark condition.

\section{OBJECTIVES}

Roundabout models available in the literature widely vary between one method and another, especially during congested conditions. Majority of these models are solely based on circulating flow for the purpose of capacity estimate of either single or dual lane roundabouts.

The relationship between maximum entry flow of large multi-lane roundabouts and their geometric and traffic parameters is investigated in this study during saturated flow condition. A multivariate 
model is developed to estimate the approach capacity of large dual or triple lane roundabouts. In order to prevent unnecessary assumptions, or keep them to the minimum, all the experimental data were gathered from roundabouts which operate under high demand flows. In order to be able to assist the relative influence of each predictor efficiently, the presence of multi-collinearity between the predictors is eliminated by removing the predictors causing collinearity. The model is capable of handling both dual and triple lane roundabouts. Most of the current models are developed for the use of single or dual lane roundabouts. The paper also calibrates several known international models to suite regional use and to have close match with both field and modeled data.

\section{METHODOLOGY AND STUDY APPROACH}

To study the association between large roundabout capacity during forced flow periods and traffic and geometric predictors, multivariate regression analysis employing backward method is utilized. The procedure followed in model development consists of eight stages.

Stage 1: All the individual traffic and geometric predictors, along with all possible joint interaction terms, are first set as variables for regression purposes.

Stage 2: Pearson correlation tests are performed on all the predictors. This is to identify the significance of linear correlation of the each predictor with respect to maximum entry flow. However, this does not necessary mean that poorly correlated individual estimators are going to be removed from the modeling process, since some might become, jointly, significant for the model in the presence of other estimators.

Stage 3: Knowing the relative influence of each predictor or interaction term, they are further analyzed individually versus the field entry flow using the following possible regression analysis: linear, quadratic, cubic, power, exponential and logarithmic. The form which produces the highest $\mathrm{R}^{2}$ is considered for further modeling provided their $\mathrm{R}^{2}$ values are not relatively low. $\mathrm{R}^{2}$ of 0.3 is set as a control limit to include the predictors for further analysis.

Stage 4: All the selected predictors in their new forms, as being liner, cubical, power, logarithmic or other forms, are reanalyzed using enter-regression model.

Stage 5: Backward least square multivariate regression analysis is then performed on the earlier predictors. The method constructs the model, iteratively, by excluding the independent traffic and geometric predictors, i.e. with the least $\mathrm{F}$ values, one at a time. The algorithm stops once the list includes no further insignificant variable at 0.05 level. The adjusted $\mathrm{R}^{2}$ values are also determined in each step.

Stage 6: The model is smoothened by removing extreme values from the data list. The data is then retested using backward multivariate regression. The excluded data were summed up to a maximum of $10 \%$ of the sample size. The modeled data and the actual ones are then compared using statistical means, such as root mean square error (RMSE) and standard error of estimate (SEE), along with the scattered plot. RMSE measures the differences between values predicted by a model and the values actually observed.

Stage 7: The model is then checked for the existence of multi-collinearity between the predictors. Collinearity might be a problem if the purpose is to estimate the contribution of individual predictors since it entangles the effects of the predictors, complicating the interpretation. However, the fitted model still is accurate since the overall model prediction is satisfactory [39]. Variance inflation factor (VIF) measures the extent of collinearity presence. The acceptable VIF values are thought to be in the range of 10 [39]. All the predictors with high VIF values are removed from the earlier model. The remaining predictors are then regressed again. The removed predictors are 
once again added to the model, one at a time, to check for other possible significant variables with reasonable VIF values. The variables are centered before considering the final model. This is to further minimize the effect of multi-collinearity.

Stage 8: The model is then compared with several international models using scattered plots, measuring RMSE, $t$-tests as necessary and paired difference standard error of mean (SEM). The paired difference SEM equals the standard deviation difference divided by the root of the sample size. The models are then calibrated to match the developed model and consequently actual Bahrain data. Each international model is calibrated by a trial multiplicative factor, which is then increased and decreased in an iterative manner until best match between the calibrated model and the developed one is achieved. For example, the slope of the model, in case of being linear, will be adjusted up and down until best match is attained with actual data. The root mean square error or residual and paired $t$-test is performed in each step for comparison purposes.

As in the UK, French and several other models, number of lanes is presented implicitly in the entry width. However, number of entry lanes is also considered in the modeling. The system will consider the predictor with higher significance for the model in case any is deemed significant.

The maximum entry flow is analyzed as per approach entry, not per individual or critical lane, since many of the considered models utilized the traffic per approach entry. This is just to stop further complications to the models which are already complex. Furthermore, researchers prefer them over individual lane determination [40]. The traffic from the various entry lanes is assumed to dissipate at equal rate during congested flows. The calculated capacities are compared with the actual demand. All the estimated capacities are also compared with their corresponding circulating flows. No environmental, lighting or pedestrian crossing factors are considered in the development of the model. Both circulating and entering vehicles are considered regardless of their relative lanepositions. In other words, no lane classification, as the vehicle being in the first, second or third lane, is considered here.

The capacity model developed here is limited to the use of medium to large roundabouts, i.e. inscribed diameter greater than $60 \mathrm{~m}$, with dual or triple lanes during heavy flow condition. Though the model is useful for the general use during various traffic flow conditions, its application during saturation or oversaturation, i.e. congested, conditions provides more convinced results since, unlike signalized intersection, unbalanced lane and approach traffic clearly influence the capacity prediction of other approaches. This is because the generated circulating and exiting traffic will be affected by such changes.

\section{DATA GATHERING}

Thirteen roundabouts across Bahrain were tested for the investigation. All the roundabouts carried heavy traffic flows, relatively large inscribed diameters, i.e. over $60 \mathrm{~m}$, dual or triple entry and circulating lanes, either four or five approaching legs, being on a main road and minimal approaching grades. These are meant to lead to better consistency in the results. The geometric parameters of the roundabouts were gathered from actual drawings, GIS maps, geo-referenced aerial photos and actual field measurements. These were necessary to cross-check the data extracted from one source with another, to measure the missing geometric parameters from the original drawings and to compare the proposed drawings with the actual ones. Table 1 shows the range of the measured values along with that recommended by the UK Ministry of Transport.

Measuring flare length, entry angle, weaving length and entry radius of narrowest right edge requires careful attention and consistent talent to have reliable data. Entry width may also be tricky and lead to different readings if measured by more than one person without clear guidance. Other 
geometric parameters are quite straightforward to measure. However, radius of central island of roundabouts with imperfect circular shape and its inscribed diameter may also require careful attention. In this study, both are considered for each approach separately. The presence of heavy vehicles and pedestrian crossing was minimal. Heavy trucks are not allowed to operate on the majority of the major intersections of the Capital during the morning peak. The presence of buses consisted of less than $1.5 \%$ of the traffic. The classified entry traffic flow counts for the selected roundabouts were collected during both morning and evening peaks for each approach. It is worth mentioning that both have been considered separately in this study. No averaging of the two values is considered, since each of the two is sensitive to the traffic flows from other approaches. This will also cover any fluctuation in the traffic flow of different approaches between the morning and the evening peaks. Nevertheless, both occur during day time in this region since the sunsets afterward. Considering traffic from each approach individually will lead to serious inaccurate estimates.

Road Directorate in Bahrain gathered the data manually for the need of this study through classified intersection counts. As a result, origin-destination data, circulating flow and exiting flow were built (Table 2). The circulating and exiting flows are quite difficult to be measured directly. Therefore, they

Table 1: Geometric characteristics of roundabouts used in the study.

\begin{tabular}{lcccc}
\hline Parameters & Abbreviation & Mean & Range & $\begin{array}{c}\text { UK recommended } \\
\text { range [2] }\end{array}$ \\
\hline Entry flow (vph) & $q_{e}$ & 1033.5 & $12-4479$ & Open \\
Inscribed diameter (m) & $D_{i}$ & 105.2 & $63-200$ & $>40(15-100)$ \\
Entry angle & $\Phi$ & $19.1^{\circ}$ & $8-33^{\circ}$ & $10-60^{\circ}$ \\
Entry radius narrowest right edge (m) & $r$ & 57.3 & $20-120$ & $6-100$ \\
Flare length (m) & $l^{\prime}$ & 34.9 & $10-96$ & $1-100$ \\
Approach half width (m) & $v$ & 7.9 & $4-10$ & $2-11$ \\
Entry width all lanes (m) & $e$ & 9.3 & $6.5-16$ & $4-15$ \\
Radius of central island (m) & $R$ & 40.1 & $24-65$ & $>31(4-91)$ \\
Width of circulating lanes (m) & $w$ & 11.0 & $8-20$ & $4-15$ \\
Width of splitter island (m) & $l_{i}$ & 30.7 & $16-82$ & Not available \\
Length of weaving section (m) & $l_{n}$ & 60.8 & $20-205$ & Open \\
Circulating flow (vph) & $q_{c}$ & 1565.2 & $48-4960$ & Open \\
Exiting flow (vph) & $q_{a}$ & 1247.9 & $3-4091$ & Not available \\
\hline
\end{tabular}

Table 2: Sample of origin-destination data for one of the tested roundabouts.

\begin{tabular}{|c|c|c|c|c|c|c|c|c|}
\hline & \multicolumn{5}{|c|}{ To } & \multirow{2}{*}{$\begin{array}{c}\text { Entering (vph) } \\
\mathrm{Q}_{\mathrm{e}} \\
\end{array}$} & \multirow{2}{*}{$\begin{array}{c}\text { Circulating (vph) } \\
\mathrm{Q}_{\mathrm{c}}\end{array}$} & \multirow{2}{*}{$\begin{array}{c}\text { Exiting (vph) } \\
\mathrm{Q}_{\mathrm{a}} \\
\end{array}$} \\
\hline & Direction & $\mathrm{N}$ & $\mathrm{E}$ & $\mathrm{S}$ & W & & & \\
\hline \multirow{5}{*}{ From } & $\mathrm{N}$ & 0 & 245 & 1005 & 45 & 1295 & 1260 & 1269 \\
\hline & $\mathrm{E}$ & 56 & 0 & 290 & 405 & 751 & 1778 & 435 \\
\hline & $\mathrm{S}$ & 1183 & 91 & 0 & 565 & 1839 & 374 & 1491 \\
\hline & $\mathrm{W}$ & 30 & 99 & 196 & 0 & 325 & 1540 & 1015 \\
\hline & Total & 1269 & 435 & 1491 & 1015 & 4210 & 4952 & 4210 \\
\hline
\end{tabular}


are considered indirectly as considered in many literatures. Average measured values, along with maximum and minimum ones, of the various collected parameters are presented in Table 1.

\section{MAIN RESULTS}

Pearson linear correlation tests (Table 3) conducted for the various individual predictors versus the maximum entry flow showed all the predictors to be significantly correlated to maximum entry flow at 0.05 level of significance except number of circulating lanes, inscribed diameter, entry angle, entry radius of narrowest right edge, flare length, radius of central island, width of splitter island and length of weaving section. Some might hold nonlinear relationship with maximum entry flow. Furthermore, some of the earlier insignificant predictors become highly significant when jointly considered with other predictors as with circulating or exiting flows.

\subsection{Model development}

Regressing all the traffic and geometric variables, along with the joint terms, showed 20 predictors, out of 60 tested ones, to be significantly affecting the maximum entry flow at 0.05 level of significance.

Table 3: Correlation tests between maximum entry flow and the main variables.

\begin{tabular}{lccc}
\hline Parameters & Abbreviation & $\begin{array}{c}\text { Pearson } \\
\text { correlation }\end{array}$ & $\begin{array}{c}\text { Level of } \\
\text { significance }\end{array}$ \\
\hline Number of entry lanes & $N_{e}$ & 0.525 & 0.000 \\
Number of circulating lanes & $N_{c}$ & 0.017 & 0.865 \\
Inscribed diameter (m) & $D_{i}$ & 0.005 & 0.963 \\
Entry angle & $\Phi$ & -0.100 & 0.325 \\
Entry radius narrowest right edge (m) & $r$ & 0.150 & 0.138 \\
Flare length (m) & $l^{\prime}$ & -0.160 & 0.115 \\
Approach half width (m) & $v$ & 0.517 & 0.000 \\
Entry width all lanes (m) & $e$ & 0.573 & 0.000 \\
Radius of central island (m) & $R$ & -0.038 & 0.710 \\
Width of circulating lanes (m) & $w$ & 0.264 & 0.008 \\
Width of splitter island (m) & $l_{i}$ & 0.185 & 0.066 \\
Length of weaving section (m) & $l_{n}$ & -0.009 & 0.927 \\
Circulating flow (vph) & $Q_{c}$ & -0.642 & 0.000 \\
Exiting flow (vph) & $Q_{a}$ & 0.762 & 0.000 \\
Circulating flow by flare length & $Q_{c} \cdot l^{\prime}$ & -0.479 & 0.000 \\
Circulating flow by inscribed diameter & $Q_{c} \cdot D$ & -0.497 & 0.000 \\
Exiting flow by inscribed diameter & $Q_{a} \cdot D$ & 0.602 & 0.000 \\
Exiting flow by entry width & $Q_{a} \cdot e$ & 0.791 & 0.000 \\
Exiting flow by approach half width & $Q_{a} \cdot v$ & 0.753 & 0.000 \\
Exiting flow by flare length & $Q_{a} \cdot l^{\prime}$ & 0.351 & 0.000 \\
Exiting flow by circulating lanes numbers & $Q_{a} \cdot N_{c}$ & 0.728 & 0.000 \\
Width by number of circulating lanes & $w \cdot N_{c}$ & 0.559 & 0.000 \\
\hline & & &
\end{tabular}


The resultant model, using backward multivariate regression analysis as presented in Table 4, showed high adjusted $\mathrm{R}^{2}$ and $\mathrm{F}$ values of 0.831 and 28 , respectively. However, all the predictors, except two, carried VIFgreater than 10; which reveal clear presence of multi-collinearity between the regressed variables. High multi-collinearity makes the relative influence of various predictors difficult to assist. In order to improve the earlier model, extreme data points are first removed from the data set by comparing the predicted maximum entry flows with actual field data. These summed up to 10 data points, which are less than the $10 \%$ limit set for the study.

The multivariate regression analysis is repeated for the development of a modified model. The new model, with better adjusted $\mathrm{R}^{2}$ and $\mathrm{F}$ values, is presented in Table 5. Multi-collinearity still exists between 13 of the 17 significant variables in the model. The new model presented drastic changes in the significant regressed variables when compared with the earlier model. Only 8 of the 17 significant predictors of the new model were presented in the earlier one. This indicates instability of at least one of the two models, probably because of the presence of high correlation between some of the regressed variables and others. Figure 1 presents the predicted maximum entry flow, as

Table 4: Characteristics of significant variables used in developing roundabout capacity model using all data points.

\begin{tabular}{|c|c|c|c|c|c|}
\hline Significant predictors & Coefficient & $\begin{array}{l}\text { Standard error } \\
\text { of estimate }\end{array}$ & $t$-test & p-value & VIF \\
\hline (Constant) & 3275.479 & 7224.6 & 0.453 & .651 & - \\
\hline Number of entry lanes & 1857.653 & 330.8 & 5.616 & .000 & 28 \\
\hline Number of circulating lane & -884.056 & 199.2 & -4.438 & .000 & 10 \\
\hline Inscribed Diameter (m) & -15.147 & 7.1 & -2.135 & .035 & 75 \\
\hline Entry angle & 88.941 & 24.7 & 3.595 & .001 & 36 \\
\hline Exiting flow (vph) & -1.741 & .594 & -2.932 & .004 & 255 \\
\hline $\mathrm{N}_{\mathrm{e}}{ }^{\mathrm{W}} \mathrm{W}$ & -114.096 & 29.431 & -3.877 & .000 & 55 \\
\hline $\mathrm{Q}_{\mathrm{a}}^{\mathrm{e} * \mathrm{r}}$ & $9.846 \mathrm{E}-6$ & $2.34 \mathrm{E}-6$ & 4.213 & .000 & 137 \\
\hline $1.419 \mathrm{~N}_{\mathrm{c}} * \mathrm{Q}_{\mathrm{a}}{ }^{1.1068}$ & .094 & .042 & 2.257 & .026 & 161 \\
\hline $899146.5-110218.7 * \log \left(D * Q_{c}\right)$ & -.066 & .019 & -3.540 & .001 & 712 \\
\hline $10.18 *\left(\mathrm{r} * \mathrm{Q}_{\mathrm{a}}\right)^{1.271}$ & $-4.689 \mathrm{E}-5$ & .000 & -3.353 & .001 & 47 \\
\hline $\begin{array}{l}63.2+0.0763\left(\mathrm{e}^{*} \mathrm{w}\right)-0.00006067 *\left(\mathrm{e}^{*} \mathrm{w}\right)^{2} \\
\quad+0.000000020127\left(\mathrm{e}^{*} \mathrm{w}\right)^{3}\end{array}$ & 263.398 & 81.24 & 3.242 & .002 & 52 \\
\hline $\begin{array}{l}26215.7-25.333\left(\mathrm{e}^{*} \mathrm{Q}_{\mathrm{c}}\right)+0.01508\left(\mathrm{e}^{*} \mathrm{Q}_{\mathrm{c}}\right)^{2} \\
\quad-0.00000336029\left(\mathrm{e}^{*} \mathrm{Q}_{\mathrm{c}}\right)^{3}\end{array}$ & $3.983 \mathrm{E}-6$ & $1.40 \mathrm{E}-5$ & 3.192 & .002 & 2 \\
\hline $24.696 *\left(\mathrm{R} * \mathrm{Q}_{\mathrm{a}}\right)^{1.0757}$ & $-4.44 \mathrm{E}-4$ & $6.63 \mathrm{E}-5$ & -6.695 & .000 & 34 \\
\hline $358439409.8-44983286.9 \log 10\left(\mathrm{Q}_{\mathrm{c}}{ }^{2 *} \mathrm{Phi}\right)$ & $8.586 \mathrm{E}-5$ & $2.30 \mathrm{E}-5$ & 3.740 & .000 & 592 \\
\hline 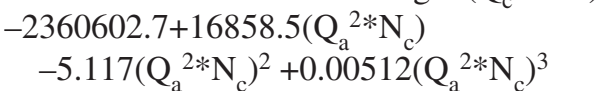 & $-1.183 \mathrm{E}-17$ & $2.02 \mathrm{E}-18$ & -5.850 & .000 & $\begin{array}{r}23 \\
249\end{array}$ \\
\hline $24.9927\left(\mathrm{Q}_{\mathrm{a}}^{2} \mathrm{D}\right)^{2.24}$ & $-9.646 \mathrm{E}-19$ & $1.67 \mathrm{E}-19$ & -5.785 & .000 & 160 \\
\hline $14.236\left(\mathrm{Q}_{\mathrm{a}}^{2 * 1}\right)^{2.135}$ & $-9.093 \mathrm{E}-17$ & $9.37 \mathrm{E}-18$ & -9.699 & .000 & 723 \\
\hline $11.581\left(\mathrm{Q}_{\mathrm{a}}^{2} * \mathrm{R}\right)^{2.21}$ & $6.752 \mathrm{E}-17$ & $7.8 \mathrm{E}-18$ & 8.641 & .000 & 92 \\
\hline $2.505332\left(\mathrm{e}^{2 *} \mathrm{Q}_{\mathrm{a}}\right)^{0.5033942}$ & -1.576 & .582 & -2.710 & .008 & 146 \\
\hline $5.791166\left(\mathrm{Q}_{\mathrm{a}}{ }^{2 *} \mathrm{w}\right)^{0.30467683}$ & 4.007 & .911 & 4.401 & .000 & \\
\hline Other Statistics & \multicolumn{5}{|c|}{$\mathrm{R}_{\mathrm{Adj}}^{2}=0.831, \mathrm{SEOE}=317, \mathrm{~F}=28, \mathrm{RMSE}=286.1, \mathrm{~N}=109$} \\
\hline
\end{tabular}


Table 5: Characteristics of significant variables used in developing roundabout capacity model with extreme data points excluded.

\begin{tabular}{|c|c|c|c|c|c|}
\hline Significant predictors & Coefficient & $\begin{array}{l}\text { Standard error } \\
\text { of estimate }\end{array}$ & $t$-test & p-value & VIF \\
\hline (Constant) & -7917.7 & 1629.755 & -4.858 & .000 & - \\
\hline Number of entry lanes & 1852.7 & 452.604 & 4.093 & .000 & 60.9 \\
\hline Number of circulating lane & -449.4 & 132.276 & -3.397 & .001 & 5.2 \\
\hline Entry radius narrowest right edge (m) & 3.6 & 1.417 & 2.505 & .014 & 1.3 \\
\hline Approach half width (m) & 375.6 & 95.283 & 3.941 & .000 & 32.4 \\
\hline Width of circulating lanes (m) & 293.5 & 82.752 & 3.547 & .001 & 57.8 \\
\hline$e^{2}$ & 8.2 & 3.122 & 2.641 & .010 & 43.8 \\
\hline $\mathrm{N}_{\mathrm{e}}{ }^{\mathrm{W}} \mathrm{W}$ & -142.5 & 38.340 & -3.715 & .000 & 120.0 \\
\hline $\begin{array}{l}1692.7-0.0003474 * \mathrm{Q}_{\mathrm{c}}{ }^{2}+2.7726 \\
\mathrm{e}-011 * \mathrm{Q}_{\mathrm{c}}{ }^{4}-6.72737 \mathrm{e}-019 * \mathrm{Q}_{\mathrm{c}}{ }^{6}\end{array}$ & .567 & .187 & 3.034 & .003 & 9.4 \\
\hline $1.419\left(\mathrm{~N}_{\mathrm{c}} * \mathrm{q}_{\mathrm{a}}\right)^{1.1068}$ & .078 & .026 & 3.046 & .003 & 72.1 \\
\hline $899146.5-110218.7 * \log \left(D * Q_{c}\right)$ & -0.00916 & .002 & -3.858 & .000 & 14.2 \\
\hline $30.358\left(\mathrm{l}^{\prime} * \mathrm{Q}_{\mathrm{a}}\right)^{1.001016}$ & 0.00018 & .000045 & -3.891 & .000 & 5.9 \\
\hline $\begin{array}{l}-2302.8+30.056\left(\mathrm{e}^{*} \mathrm{Q}_{\mathrm{a}}\right)-.022958\left(\mathrm{e}^{*} \mathrm{Q}_{\mathrm{a}}\right)^{2} \\
\quad+.0000070335\left(\mathrm{e}^{*} \mathrm{Q}_{\mathrm{a}}\right)^{3}\end{array}$ & 4.337E-6 & $8.16 \mathrm{E}-7$ & 5.317 & .000 & 35.6 \\
\hline $68288.2-7698.79 * \log \left(w^{*} \mathrm{Q}_{\mathrm{c}}\right)$ & .154 & .047 & 3.311 & .001 & 22.7 \\
\hline $\begin{array}{l}-1523805792+93128.9\left(\mathrm{Q}_{\mathrm{a}}^{2 *} \mathrm{e}\right) \\
\quad-92.9117 *\left(\mathrm{Q}_{\mathrm{a}}{ }^{2 *} \mathrm{e}\right)^{2}+.0314 *\left(\mathrm{Q}_{\mathrm{a}}{ }^{2 *} \mathrm{e}\right)^{3}\end{array}$ & $-1.514 \mathrm{E}-20$ & $3.0 \mathrm{E}-21$ & -5.027 & .000 & 18.9 \\
\hline $2.61972 *\left(v^{2} r^{*} Q_{a}\right)^{0.51759}$ & -3.787 & .884 & -4.286 & .000 & 219.3 \\
\hline $2.50533 *\left(\mathrm{e}^{2 *} \mathrm{Q}_{\mathrm{a}}\right)^{0.503394}$ & -1.853 & .824 & -2.249 & .027 & 231.8 \\
\hline $5.79117 *\left(\mathrm{Q}_{\mathrm{a}}^{2 * \mathrm{w}}\right)^{0.3046768}$ & 3.649 & .750 & 4.865 & .000 & 120.7 \\
\hline Other Statistics & \multicolumn{5}{|c|}{$\mathrm{R}_{\mathrm{Adj}}^{2}=0.834, \mathrm{SEOE}=276, \mathrm{~F}=30, \mathrm{RMSE}=250.8, \mathrm{~N}=99$} \\
\hline
\end{tabular}

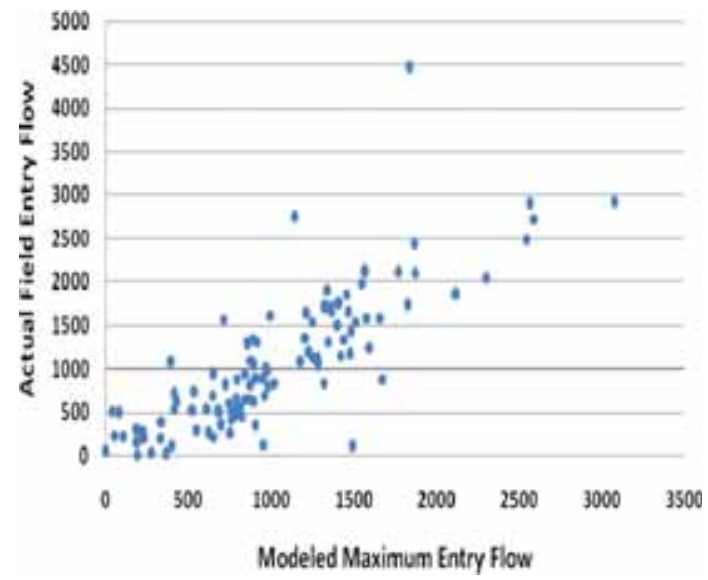

Figure 1: Modeled entry capacity versus field entry capacity. 
per the earlier mentioned model and shown in Table 5, versus actual field data. The whole data set is considered in the figure. The figure shows a reasonably well packed data, except few outlaying ones which were removed during the model development. The model looks fairly reasonable in predicting maximum entry flow.

In order to resolve the undesirable collinearity between the various regressed variables, the earlier model is retested using series of stepwise and backward regression analysis. The resultant model is presented in Table 6 . The model can be illustrated in the following form, after being rearranged:

$$
\begin{aligned}
& Q_{e}=\mathrm{f}\left(Q_{c}, D\right)+\mathrm{f}\left(Q_{a}, e, l^{\prime}, N_{c}\right)+\mathrm{f}\left(N_{e}, N_{c}, w\right) \\
& \mathrm{f}\left(Q_{c}, D\right)=-1973.8-0.000281 Q_{c}{ }^{2}+2.2412 \mathrm{E}-11 Q_{c}{ }^{4}-5.438 \mathrm{E}-19 Q_{c}{ }^{6}+409.7 * \log \left(D^{*} q_{c}\right) \\
& \text { subject to: } 60 \mathrm{~m}<D<200 \mathrm{~m} \\
& \mathrm{f}\left(Q_{a}, e, l^{\prime}, N_{c}\right)= 0.00005921\left(e^{*} q_{a}\right)-(4.523 \mathrm{E}-8)\left(e^{*} q_{a}\right)^{2}+(1.3856 \mathrm{E}-11)\left(e^{*} q_{a}\right)^{3}-(8.305 \mathrm{E}-16) \\
&\left(q_{a}^{2}{ }^{2} e\right)+8.286 \mathrm{E}-19\left(q_{a}^{4 *} e^{2}\right)-(2.798 \mathrm{E}-22)\left(q_{a}{ }^{6} e^{3}\right)-0.00464\left(l^{\prime *} q_{a}\right)^{1.001016} \\
&+0.0563\left(N_{c}{ }^{*} q_{a}\right)^{1.1068} \\
& \text { subject to: } N_{c}=2 \text { or } 3,10 \mathrm{~m}<l^{\prime}<96 \mathrm{~m}, 6 \mathrm{~m}<e<16 \mathrm{~m} \\
& \mathrm{f}\left(N_{e^{\prime}}, N_{c}, w\right)= 462.2+387.4 N_{e}+48.3 w-298.9 N_{c} \\
& \text { subject to: } N_{e}=2 \text { or } 3, N_{c}=2 \text { or } 3,8 \mathrm{~m}<w<20 \mathrm{~m}
\end{aligned}
$$

\begin{tabular}{|c|c|c|c|c|c|c|}
\hline Significant predictors & Coefficient & $\begin{array}{l}\text { Standard } \\
\text { error of } \\
\text { estimate }\end{array}$ & $t$-test & $\mathrm{p}$-value & VIF & $\begin{array}{l}\text { Mean } \\
\text { model } \\
\text { values }\end{array}$ \\
\hline (Constant) & 462.2 & 472.1 & 0.98 & 0.330 & - & - \\
\hline Number of entry lanes & 387.4 & 107.7 & 3.60 & 0.001 & 3.0 & 915.7 \\
\hline Number of circulating lane & -298.9 & 85.9 & -3.48 & 0.001 & 1.9 & -793.3 \\
\hline Width of circulating lanes (m) & 48.3 & 15.0 & 3.22 & 0.002 & 1.7 & 525.8 \\
\hline $\begin{array}{c}1692.7-0.000347 \mathrm{Q}_{\mathrm{c}}{ }^{2}+2.77256 \mathrm{e} \\
-11 \mathrm{Q}_{\mathrm{c}}^{4}-6.7274 \mathrm{e}-19 \mathrm{Q}_{\mathrm{c}}^{6}\end{array}$ & 0.808365 & 0.167 & 4.84 & 0.000 & 6.7 & 835.5 \\
\hline $30.358\left(\mathrm{l}^{\mathrm{c}} * \mathrm{Q}_{\mathrm{a}}\right)^{1.001016}$ & -0.000153 & 0.000037 & -4.12 & 0.000 & 3.6 & -196.2 \\
\hline $1.419\left(\mathrm{Nc}^{*} \mathrm{Q}_{\mathrm{a}}\right)^{1.1068}$ & 0.0396640 & 0.008137 & 4.88 & 0.000 & 6.5 & 457.6 \\
\hline $899146.5-110218.7 * \log \left(D * Q_{c}\right)$ & -0.003717 & 0.001478 & -2.52 & 0.014 & 4.9 & -1254.9 \\
\hline $\begin{array}{l}-1523805792+93128.9\left(\mathrm{Q}_{\mathrm{a}}^{2 * \mathrm{e})}\right. \\
\quad-92.9117\left(\mathrm{Q}_{\mathrm{a}}^{2 *} \mathrm{e}\right)^{2} \\
\quad+0.03137\left(\mathrm{Q}_{\mathrm{a}}^{2 * \mathrm{e}}\right)^{3}\end{array}$ & $-8.918 \mathrm{E}-21$ & $2.24 \mathrm{E}-21$ & -3.98 & 0.000 & 9.3 & -76.8 \\
\hline $\begin{array}{l}-2302.8+30.056\left(\mathrm{e}^{*} \mathrm{Q}_{\mathrm{a}}\right) \\
\quad-0.022958\left(\mathrm{e}^{*} \mathrm{Q}_{\mathrm{a}}\right)^{2} \\
\quad+0.0000070335\left(\mathrm{e}^{*} \mathrm{Q}_{\mathrm{a}}\right)^{3}\end{array}$ & 0.00000197 & $6.0 \mathrm{E}-21$ & 4.06 & 0.000 & 11.0 & 125.8 \\
\hline Other Statistics & $\mathrm{R}_{\mathrm{Adj}}^{2}=0.812$ & $\mathrm{SEOE}=292, \mathrm{~F}$ & $\mathrm{~F}=48, \mathrm{RI}$ & . & $8.4, \mathrm{~N}=$ & \\
\hline
\end{tabular}

where $Q_{e}$ is the maximum entry flow (vph), $Q_{c}$ the circulating flow (vph), $Q_{a}$ the exiting flow of the vehicles to the left of the corresponding entry (vph), $l^{\prime}$ the flare length $(\mathrm{m}), D$ the inscribed diameter (m), $e$ the entry width of all lanes $(\mathrm{m}), N_{c}$ the number of circulating lanes, $N_{e}$ the number of entry lanes and $w$ is the width of circulating lanes $(\mathrm{m})$.

Table 6: Characteristics of significant modeled variables after the collinearity between regressed predictors been diagnosed. 
For example given $\mathrm{Q}_{\mathrm{c}}=848 \mathrm{vph}, \mathrm{Q}_{\mathrm{a}}=1887 \mathrm{vph}, \mathrm{l}^{\prime}=13 \mathrm{~m}, \mathrm{D}=150 \mathrm{~m}, \mathrm{e}=10 \mathrm{~m}, \mathrm{~N}_{\mathrm{c}}=2, \mathrm{~N}_{\mathrm{e}}=2$ and $\mathrm{w}=10 \mathrm{~m}$; the predicted maximum entry flow $\left(\mathrm{Q}_{\mathrm{e}}\right)$, as per the above model, is $1512 \mathrm{vph}$. The actual field entry flow showed to be $1540 \mathrm{vph}$.

The model fits the data sufficiently well, since $F$ and adjusted $R^{2}$ values are fairly high. i.e. 48 and 0.812 , respectively. This can also be observed from a well grouped data, at around $45^{\circ}$, of predicted maximum entry flow versus observed ones shown in Fig. 2. The slight scattering of the presented data is due to the variability in drivers' response towards oncoming entry headways and the differences in the geometric and traffic data between one roundabout and another. The improved model showed slightly lower adjusted $\mathrm{R}^{2}$ value than the ones shown earlier (Table 5). Moreover, both the root mean square error (RMSE) and standard error of estimate (SEOE) also showed slightly higher values compared with the earlier model. The model though being very reasonable statistically, yet the earlier findings indicate slightly greater dispersion around the modeled values. In other words, the earlier model (Table 5), regardless of the presence of collinearity between the involved variables, estimates the entry capacity slightly better than that presented in equations 1 to 4 (Table 6) in which the influence of collinearity between the various regressed variables are kept to the minimum. The model presented in Equations 1 to 4 (Table 6) being slightly simpler and strongly more stable than the model presented in Table 5 overcomes the earlier advantage of the latter model.

While the dominant parameters of the improved model (Equations 1-4) are circulating and exiting flows, the important geometric parameters consist of number of entry and circulating lanes, inscribed diameter, entry width, flare length and width of circulating lanes. This does not mean that other geometric parameters are not important for the design purposes of roundabouts. The model simply indicates that all the other parameters are insignificant for roundabouts' capacity estimation in the presence of the earlier significant parameters.

The overall average predicted capacity using the developed model, employing Equations 1 to 4, for all the data points, inclusive of the out laying ones, equals $1001.3 \mathrm{vph}$ with SEM $57.5 \mathrm{vph}$. The mean modeled values of each significant term are presented in the last column of Table 6 . The average of the function covering circulating flow, i.e. $\mathrm{f}\left(\mathrm{Q}_{c}, \mathrm{D}\right)$ presented in Equation 2, showed to be $-419.4 \mathrm{vph}$, i.e. -1254.9 for the cubical term and 835.5 for the logarithmic term. Similarly, the

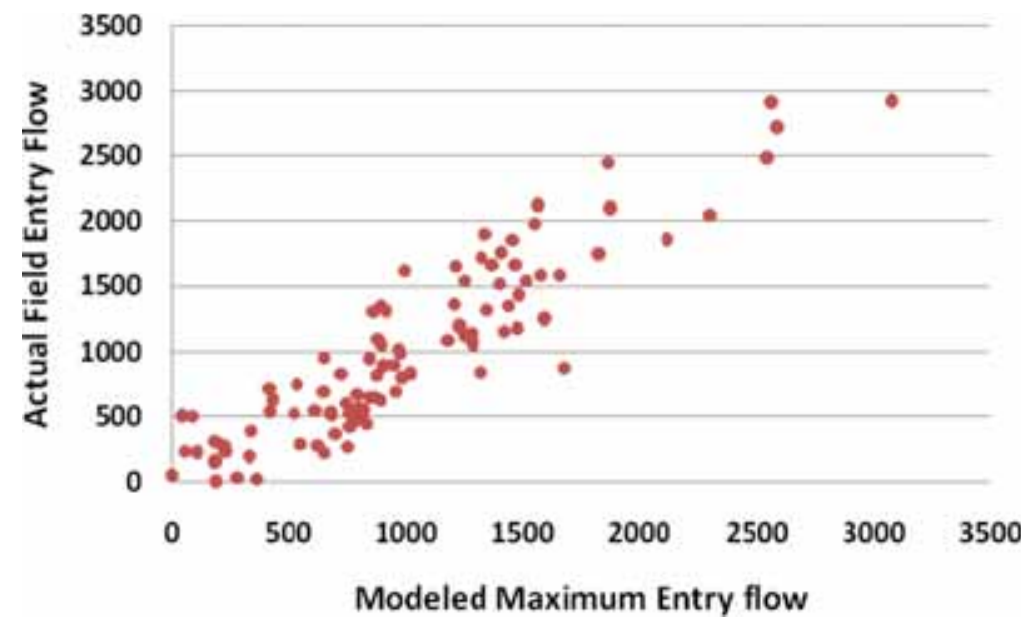

Figure 2: Modeled capacity versus actual capacity after removing extreme data and resolving the presence of multi-collinearity between the predictors. 
average of the function covering the exiting flow, i.e. $f\left(Q_{a}, e, l^{\prime}, N_{c}\right)$ presented in Equation 3, showed to be $310.4 \mathrm{vph}$, which is the sum of 125.8 and -76.8 for the two cubical terms involving entry width (e) and 457.6 and -196.2 for the two power terms involving number of circulating lanes $\left(\mathrm{N}_{\mathrm{c}}\right)$ and flare length (l'). The average of the function covering solely the geometric predictors, i.e. $f\left(N_{e}, N_{c}\right.$, w) presented in Equation 4, excluding the constant term, showed to be $648.2 \mathrm{vph}$, resulting from 915.7 for the entry lanes $\left(\mathrm{N}_{\mathrm{e}}\right),-793.3$ for circulating lanes $\left(\mathrm{N}_{\mathrm{c}}\right)$ and 525.8 for circulating width $(\mathrm{w})$. In general, one may say that the geometric terms alone showed to have the highest influence on the predicted entry capacity, with a positive end result, followed by the function involving circulating flow, with a negative end result, and then the function involving exiting flow, with a positive final result. The joint term covering circulating flow and inscribed diameter showed the highest, negative, influence on the entry flow. However, the term is counterbalanced by the cubical circulating flow term. One may also note that number of entry and circulating lanes are dominant predictors in estimating maximum entry flow.

It is clear from the earlier findings that $f\left(\mathrm{~N}_{e}, N_{c}, w\right)$ has more than twice the influence of $f\left(Q_{a}, e\right.$, $\left.l^{\prime}, N_{c}\right)$ on the entry capacity. The latter has less than one-third the influence of $f\left(Q_{c}, D\right)$ on the prediction of entry capacity.

The earlier process was repeated by centering the variables, i.e. replacing each variable with the difference between its mean and original value. The results showed the very same variables to be significant. In fact, the coefficients were also the same except for the constant parameter.

The results also showed that as the exiting flow increases, regardless of the enfluence of geometric parameters, so does the entry flow (Fig. 3). This matches the expectations, since as a vehicle exits out from a large roundabout other vehicles from a corresponding entry approach will have the chance to enter the roundabout due to the resulting larger time and space gaps because of the exiting traffic. However, in reality the situation on multilane roundabouts is more complicated than simply having individual gaps since an exiting vehicle from an individual lane might not lead to a sufficiently acceptable gap for entering drivers to get into the roundabout, but it might encourage some drivers to get through during forced flow conditions. The French model also showed a positive association of exiting flow on entry flow [41]. However, the NCHRP report on roundabouts showed no significant influence of exiting flow on entry capacity [18], which is contradicting with the finding here, as the model showed otherwise. The relationship between the two showed the following negative linear model:

$$
Q_{c}=2425-0.693 Q_{a}\left(\mathrm{R}^{2}{ }_{\mathrm{Adj}}=0.36 \& \mathrm{VIF}=1.0\right)
$$

The relationship showed less than moderate adjusted $\mathrm{R}^{2}$ value due to the scattering nature of the data. The VIF value reveals the presence of no collinearity since only one predictor is involved. On the other hand, the circulating flow and the modeled entry flow, as in all the international models, are inversely related to each other (Fig. 4).

\subsection{Calibration of international models for the regional use}

Varying differences in the predicted entry capacities were observed between the developed model and various considered international models. Pearson correlation tests showed no significant correlation between the actual field data and any of the considered models. In other words, most of the models do not linearly fit Bahrain data without being calibrated. Consequently, the model developed here also showed no significant correlation, in the predicted entry capacity, with most of the considered international models. Paired $t$-tests showed significant differences between the entry flows 

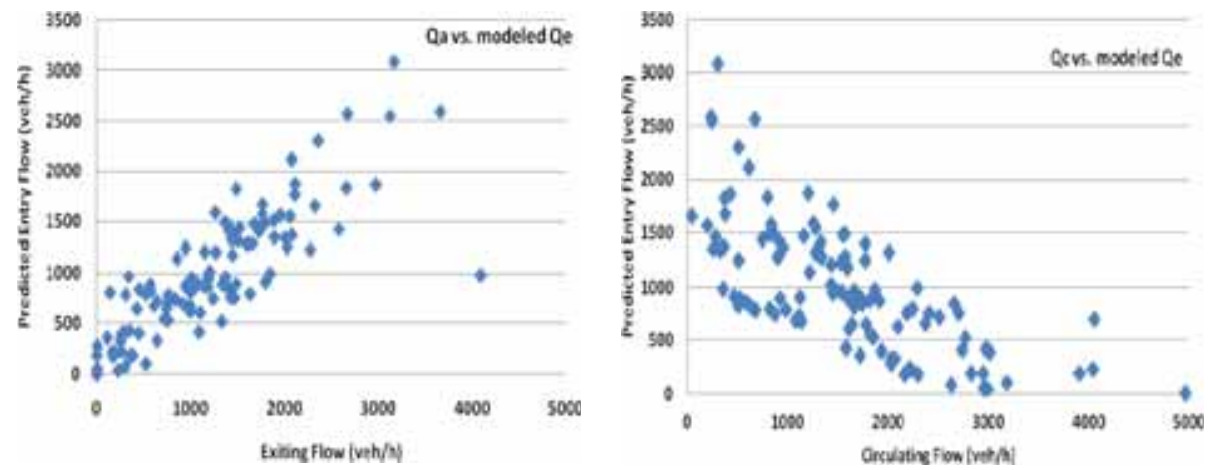

Figures $3 \& 4$ : Modeled entry flow versus actual exiting and circulating flows.

Table 7: RMSE of actual entry flows compared with some international models.

\begin{tabular}{crrrrrrr}
\hline RB & UK & aaSIDRA & FRENCH & GERMAN & SWISS & USHCM & USFHWA \\
\hline All & 1087 & 1610 & 1150 & 607 & 803 & 681 & 715 \\
$\mathbf{1}$ & 1285 & 1719 & 1238 & 427 & 708 & 522 & 659 \\
$\mathbf{2}$ & 651 & 919 & 482 & 484 & 392 & 503 & 429 \\
$\mathbf{3}$ & 641 & 894 & 328 & 370 & 389 & 371 & 333 \\
$\mathbf{4}$ & 668 & 1114 & 1183 & 724 & 973 & 536 & 507 \\
$\mathbf{5}$ & 724 & 474 & 529 & 707 & 840 & 733 & 278 \\
$\mathbf{6}$ & 494 & 671 & 532 & 837 & 872 & 808 & 481 \\
$\mathbf{7}$ & 855 & 1701 & 724 & 268 & 615 & 318 & 839 \\
$\mathbf{8}$ & 863 & 1968 & 1018 & 553 & 908 & 668 & 1251 \\
$\mathbf{9}$ & 1209 & 2027 & 1121 & 3589 & 786 & 598 & 621 \\
$\mathbf{1 0}$ & 1951 & 2419 & 2160 & 508 & 1074 & 1022 & 920 \\
$\mathbf{1 1}$ & 1022 & 1996 & 1127 & 1150 & 1251 & 1167 & 1149 \\
$\mathbf{1 2}$ & 1779 & 1595 & 1800 & 542 & 382 & 398 & 432 \\
$\mathbf{1 3}$ & 1001 & 2000 & 1356 & 237 & 669 & 592 & 584 \\
\hline
\end{tabular}

predicted through the model developed here and those from the international models, except the HCM. In other words, all the models, except HCM model, differed significantly from the developed model. The HCM model matches the developed model closely well.

Confirming the above findings, RMSE showed relatively high residual differences between the developed model and those predicted from several international models (Table 7). The RMSE varied between 607 in the case of German model to 1610 in the case of aaSIDRA model. In fact, the earlier variation did not differ much when each roundabout was considered individually (Table 7). Such differences confirm the significant differences between the developed model and other available models. In fact, wide variations in RMSE between the various models reveal the necessity of developing a model which addresses behavioral and cultural differences efficiently.

Such clear differences also call for careful adjustments in the international models to suite regional use. This is carried out through lowering and raising the models linearly till they closely match the 
Table 8: Calibration of international models compared with the developed model for large multi-lanes' roundabouts.

\begin{tabular}{|c|c|c|c|c|c|c|c|}
\hline \multirow[b]{2}{*}{$\begin{array}{l}\text { Considered } \\
\text { model }\end{array}$} & \multirow[b]{2}{*}{$\begin{array}{l}\text { Calibration } \\
\text { factor }\end{array}$} & \multicolumn{2}{|c|}{ Mean values } & \multirow{2}{*}{$\begin{array}{c}\text { Paired } \\
\text { difference } \\
\text { SEM }\end{array}$} & \multirow[b]{2}{*}{$\begin{array}{l}\text { Pearson } \\
\text { correlation }\end{array}$} & \multicolumn{2}{|c|}{$\begin{array}{l}\text { RMSE: international } \\
\text { models vs. }\end{array}$} \\
\hline & & $\begin{array}{l}\text { Calibrated } \\
\text { model }\end{array}$ & $\begin{array}{l}\text { Developed } \\
\text { model }\end{array}$ & & & $\begin{array}{l}\text { Modeled } \\
\text { data }\end{array}$ & $\begin{array}{l}\text { Actual } \\
\text { data }\end{array}$ \\
\hline UK & 0.538 & 998.0 & 1001.3 & 32.7 & 0.822 & 342 & 440 \\
\hline aaSIDRA & 0.445 & 933.9 & 1001.3 & 38.3 & 0.767 & 405 & 494 \\
\hline French & 0.520 & 921.9 & 995.2 & 33.8 & 0.829 & 359 & 433 \\
\hline German & 1.060 & 937.0 & 1001.3 & 38.6 & 0.761 & 408 & 493 \\
\hline Swiss & 0.7425 & 858.5 & 1001.3 & 47.7 & 0.655 & 518 & 602 \\
\hline USHCM2010* & 0.919 & 853.4 & 964.7 & 68.7 & 0.292 & 559 & 567 \\
\hline US FHWA & 0.745 & 993.9 & 1001.3 & 39.8 & 0.723 & 415 & 507 \\
\hline
\end{tabular}

*Only two lanes.

developed model, or till the field data is achieved. In other words, the slope is adjusted at fixed rate using iterative method. The best adjustment factors leading to a close match of the entry capacity, of the various tested models, with the developed model are presented in Table 8 . The necessary statistics, such as mean values, Pearson correlation tests, standard error of the mean of the paired difference and root mean square of error or residual (RMSE) are presented in the table along with the calibration factors leading to the least RMSE. The predicted entry capacities for the various calibrated models compared with the developed model are presented in Figs 5-7. One may also try adjusting the earlier models in an exponential, or other nonlinear, manner, since several international models involve an exponential term in their development, or in part of them. However, this is beyond our scope here and it is all the more difficult for the practitioners to employ them.

The following international models required the greatest adjustment factors so as to closely match the developed model, and consequently the Bahrain field data (Table 8): aaSIDRA, UK and French models. Their corresponding adjustment factors, based on the lowest RMSE between the predicted entry capacity of the calibrated international model and that predicted from the developed model, were as follows: $0.475,0.537$ and 0.560 , respectively. The earlier values reveal high over-predictions of entry capacities. These are as high as twice the values gathered from the field in Bahrain. All the earlier models involve quite extensive geometric parameters and mathematical calculations when compared with other international models. On the other hand, the German method required minimal adjustment to match the developed model and the field data. An adjustment factor of 1.060 leads to a close match with the developed model (Table 8 and Fig. 6). The factor indicates a difference of around $6 \%$ from the developed model. The US HCM method also required low adjustment factors to match the developed model. It required an adjustment factor of 0.919 (Table 8 and Fig. 7). In other words, the HCM model overestimates the roundabout entry capacity in Bahrain by around $8 \%$. The Swiss and the US FHWA models overestimate the capacity by around one-fourth. It is quite interesting to mention that the latter three models require no geometric parameters for the estimation of entry capacity. They are simply circulating flow-dependent. The question of why simpler models required little adjustments to suite the regional use when compared with more complicated and comprehensive ones, calls for further investigation. 

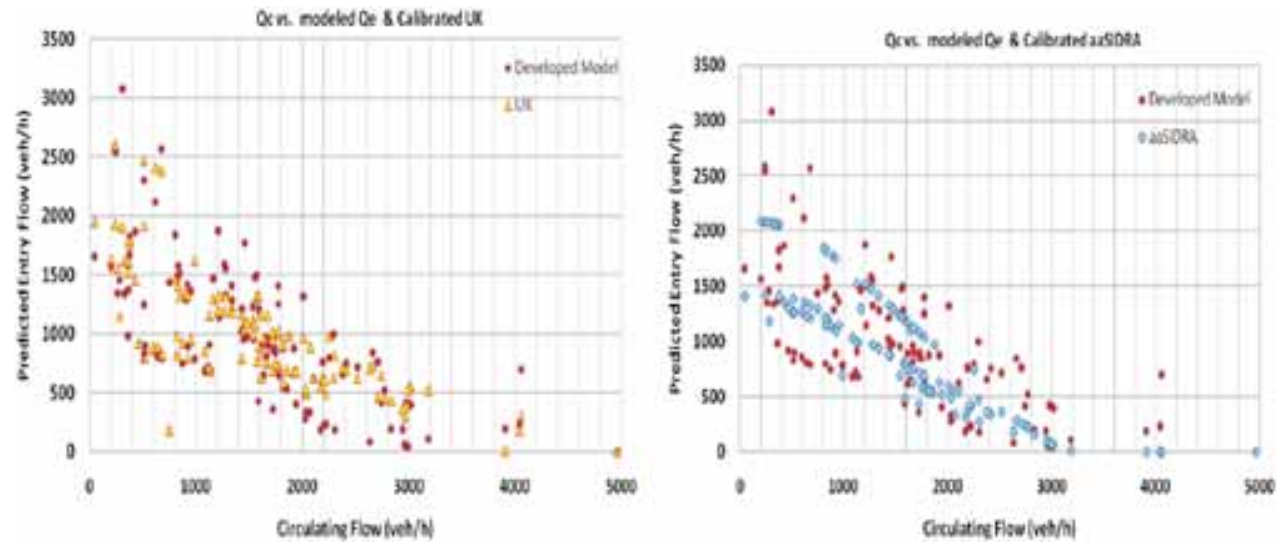

Figure 5: Predicted entry flow versus calibrated UK and aaSIDRA models.
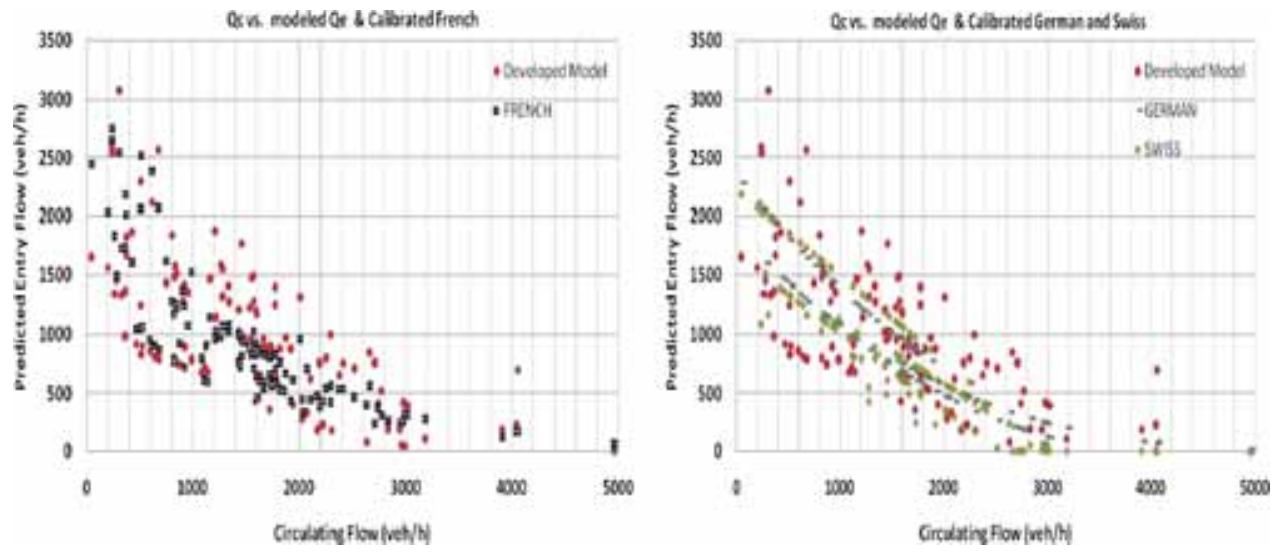

Figure 6: Predicted entry flow versus calibrated German, Swiss and French models.

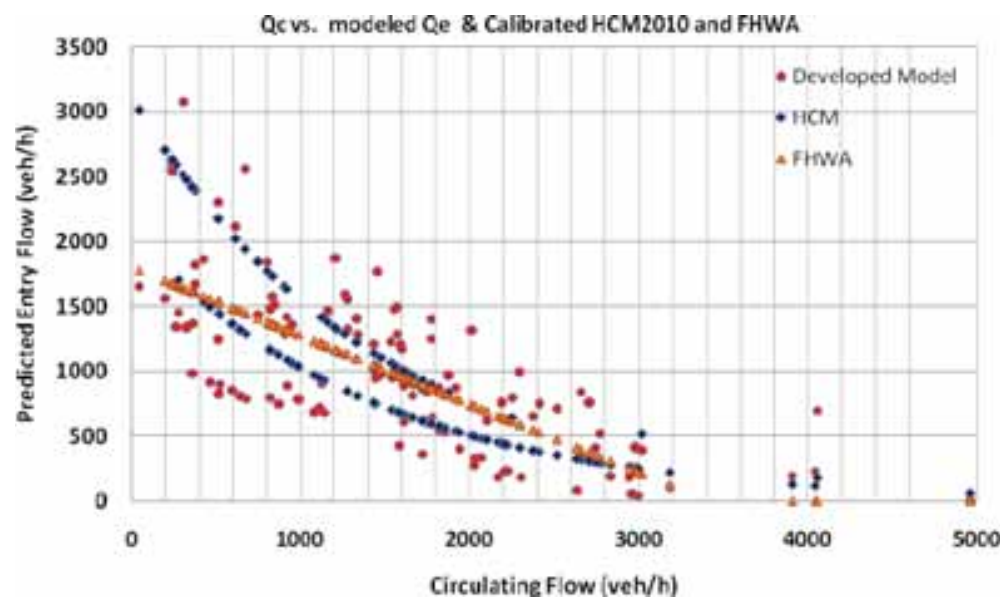

Figure 7: Predicted entry flow versus calibrated US models. 
All the calibrated models showed highly strong association with the developed model. The paired $t$-test showed insignificant differences between the calibrated values and those predicted from the model. Pearson correlation tests also showed strong linear relationships between the two (Table 8). These mean that entry flows obtained through each of the earlier calibrated models are similar to those predicted from the developed model and the actual data. Figure 8 shows the scatter plot of the predicted entry capacities using the earlier calibrated models versus the actual field data. The calibrated UK and French models show very reasonable match with actual data, regardless of few clearly outlaying data points. Both models are developed based on empirical models. The French model (Table 8) showed slightly lower average modeled capacity. This is because of the exclusion of one extra data point since it was highly out of the range in the French model. This is probably because of the involvement of exiting flow in the capacity prediction.
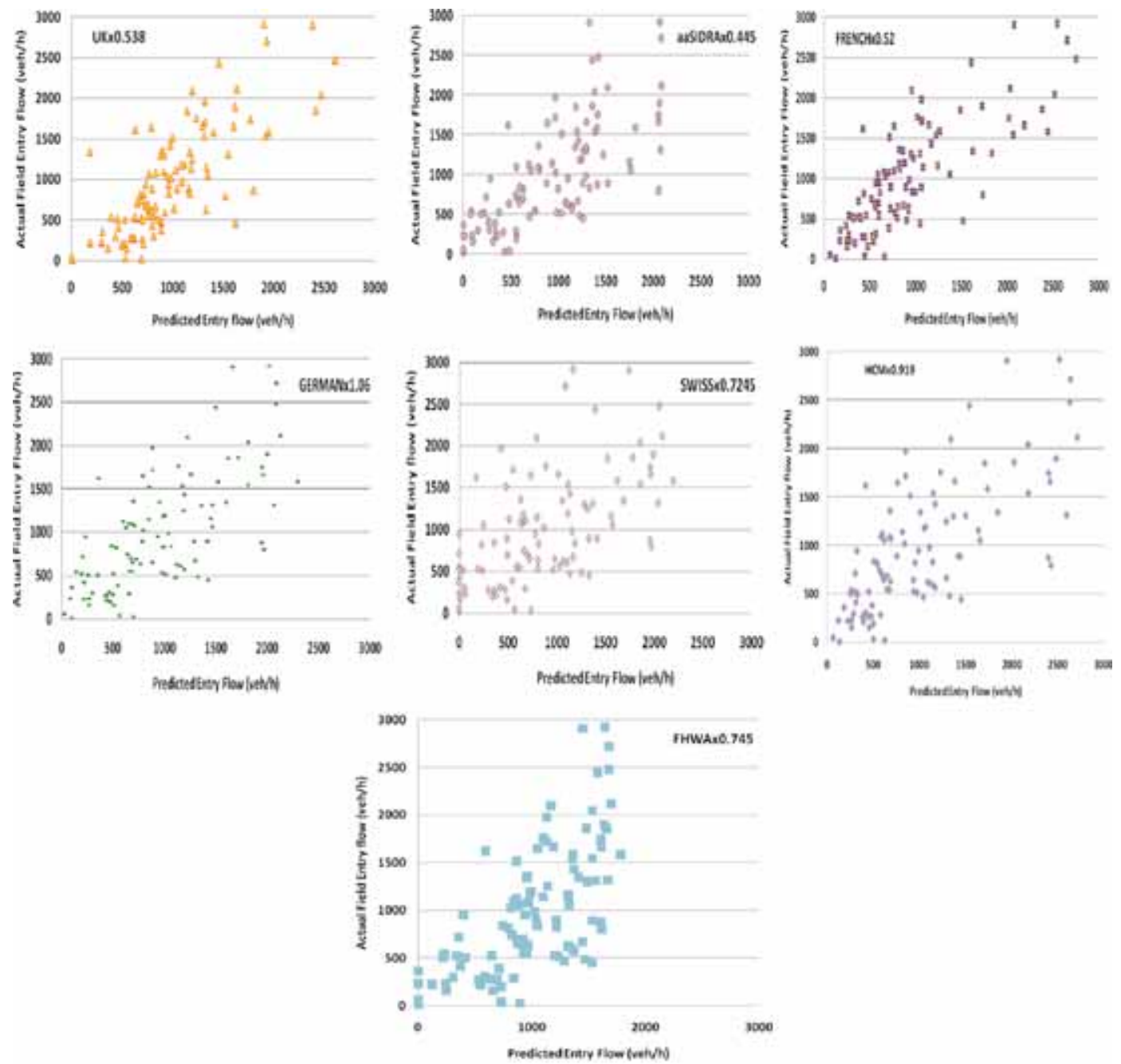

Figure 8: Roundabout entry capacity using calibrated international models vs. actual data. 
Such varying calibrating values lead to a legitimate question: What are the reasons behind such differences? While part of the reason might be due to the behavioral differences between the drivers in different parts of the world, leading to differences in acceptable entry headways at roundabout, other parts might be due to the model development, assumptions made and accuracy of gathered data. While the data for most of the models were collected for the general use of the model, the data for the model developed here were collected during forced flow conditions. Besides all, data collected from roundabouts might generally be classified as uneven. Differences in average vehicle length might also have an influence, since it is probably higher in the Arabian Gulf area when compared with Britain, France and many other developed countries. Average vehicle length in this region might be comparable to that in the States, Switzerland and Germany. Geometric differences might have influence, as well. For example, the roundabouts used in this study are considered to be relatively large. Akçelik [6, 26], who developed the aaSIDRA model, also observed clear reductions in capacity during high demand flows. Such differences at saturated flows were questioned by Russell and Rys [11]. Stanek and Milan [16] also questioned the suitability of UK RODEL and aaSIDRA models during saturation flows. Furthermore, the non-calibrated UK model overestimated the roundabout critical lane capacity in USA as well $[20,42]$. All these, along many others, need to be further researched.

\section{CONCLUSIONS AND RECOMMENDATIONS}

A multivariate model is developed for the prediction of maximum entry flow of large multi-lane roundabouts during heavy demand condition. The model estimates the entry capacity for a given set of circulating and exiting flows, number of entry and circulating lanes, entry and circulating widths, inscribed diameter and flare length. Fourteen other predictors showed to be insignificant, in the presence of the earlier significant ones, for the capacity prediction after being treated for multi-collinearity. The relative influence of the terms involving exiting flows on the prediction of the entry capacity showed to be one-half of those involving, solely, number of entry and circulating lanes, and circulating width. Their influence on the entry capacity is also lesser than the terms involving circulating flows by one-third. Knowledge of the relative influence of significant estimators will assist the designers and the planers towards the achievement of optimal capacity for a set of geometric and traffic parameters. This is especially true for multi-lane roundabouts since most of the current models are developed to suite single or dual lane roundabouts.

The model matched the field data reasonably well. The model along with the actual field data showed poor match with many international models. As a result, seven international models were calibrated through adjustment factors in an iterative manner. The UK, aaSIDRA and French models were reduced by around half to match the developed model and the field data. The Swiss and the US FHWA models required reductions of about one-fourth. The German and the US HCM models required an adjustment of less than $8 \%$. Though the differences might partially be due to the behavioral, cultural and enforcement differences, such varying results require more in-depth research. The procedure followed here is worth being researched and adopted for the general use elsewhere.

The findings, along with other parameters, are useful to be considered by the urban planners as when to shift from one type of intersection control into another involving roundabouts, and vice versa.

\section{ACKNOWLEDGMENTS}

The author wishes to thank Z. Saleh, A. Jaafar, H. Qadhi and Bahrain Road Directorate, Ministry of Public Work for their assistance in gathering the data. 


\section{REFERENCES}

[1] Guicheet, B., Evolution of roundabouts in France, National Roundabout Conference, TRB, Colorado, USA, 2005.

[2] Salter, R.J., Highway Traffic Analysis and Design, 2nd edn, Macmillan: UK, 1989.

[3] Pratelli, A. \& Souleyrette, R.B. Visibility, perception and roundabout safety, WIT Transactions on the Built Environment, vol. 107, Proceedings Urban Transport XV Urban Transport and the Environment, ed. Brebbia, C.A., WIT press: UK, pp. 577-588, 2009.

[4] Al-Madani, H.M.N., Dynamic vehicular delay comparison between a police-controlled roundabout and a traffic signal. Transportation Res, 37A, 681-688, 2003.

[5] Taekroutok, T., Modern roundabouts for Oregon, Department of Transportation, Research Unit, OR98-SRS22: Salem, USA, 1998.

[6] Akcelik, R., Chung, E. \& Besley, M., Performance of roundabouts under heavy demand conditions. Road Transport Res, 5(2), 36-50, 1996. Victoria, Australia.

[7] Akcelik and Associates, aaSIDRA 2.1 in put Guide: Roundabout Data, Revised Version, Akcelik and Associates Pty Ltd,: Greythorn, Melbourne, Australia, 2005.

[8] Hollis, E., Semmens. M.C. \& Dennis, S.L., ARCADY: A Computer Program to Model Capacities, Queues and Delays at Roundabouts, Transport and Road Research Laboratories: Crowthorne, Report LR 940, 1982.

[9] Tenekci, G., Montgomery, F. \& Wainaina, S., Roundabout capacity in adverse weather and light conditions, Transport, 163, 29-39, Proceedings of the Institution of Civil Engineers, 2010.

[10] Transportation Research Board, Highway Capacity Manual, National Research Council, TRB, SR 209: Washington D.C., 2010.

[11] Russell, E. \& Rys, M., Modeling Traffic Flows and Capacities At Roundabout, MBTC 1099, Kansas State University: Manhattan, USA, 2000.

[12] National Cooperative Highway Research Program, Appendixes to NCHRP Report 572: Roundabouts in the United States, NCHRP Web-Only Document 94, Final Report for NCHRP Project 3-65: USA, 2006.

[13] Kimber, R.M., Gap acceptance and empiricism in capacity prediction. Transportation Sci, 23(2), 100-111, 1989. doi: http://dx.doi.org/10.1287/trsc.23.2.100

[14] Russell, E. \& Rys, M., Modeling Traffic Flows and Capacities At Roundabout, MBTC 1099, Kansas State University: Manhattan, USA, 2000.

[15] Fisk, C.S., Traffic performance analysis at roundabouts. Transportation Res, 25B, 89-102, 1991. doi: http://dx.doi.org/10.1016/0191-2615(91)90016-C

[16] Boxill, S.A., An Evaluation of 3-D Traffic Simulation Modeling Capabilities, Report 167621 1, Center for Transportation Training and Research, Texas, Southern University: Houston, USA, 2007.

[17] Stanek, D. \& Milam, R.T., High-Capacity roundabout intersection analysis: going around in circles, National Roundabout Conference, TRB, Colorado, USA, 2005.

[18] Kimber, R.M., The Traffic Capacity of Roundabouts, TRRL, LR942, Crowthorne, Berkshire, UK, 1980.

[19] Al-Madani, H.M.N., Capacity of Large Dual And Triple-Lanes Roundabouts During Heavy Demand Conditions, Arabian Journal of Science and Engineering-Engineering, King Fahad University of Petroleum \& Minerals: Dhahran, Saudi Arabia, 2012. In press.

[20] Pratelli, A., Design of modern roundabout in urban traffic system, WIT Transactions on the Built Environment, vol. 89, Proceedings Urban Transport XII Urban Transport and the Environment. Ed. Brebbia, C. A., WIT press, UK, 2006. 
[21] Jacquemart, G., Modern Roundabout Practice in the United States, Synthesis of Highway Practice 264, Transportation Research Board: Washington, D.C., USA, 1998.

[22] Crown, R.B., RODEL1: Interactive Roundabout Design (Software Manual), RODEL Software Ltd. and Council: Stoke-on-Trent, 1987.

[23] Kimber, R M. \& Hollis, M., Traffic Queues and Delays at Road Junctions, Transport and Road Research Laboratory, LR909: Crowthorne, Berkshire, UK, 1979.

[24] Robinson, B.W. \& Rodegerdts, L.A., Capacity and Performance of Roundabouts: A Summary of Recommendations in the FHWA Roundabout Guide, Kitttelson \& Associates, Inc., USA, 2009./ntl.bts.gov/lib/8000/8500/8596/36_29.pdf/(as on 10 th Dec. 2009).

[25] National Cooperative Highway Research Programs (NCHRP), Roundabouts in the United States, NCHRP Report 572, Transportation Research Board: Washington, D.C., 2007.

[26] Transportation Research Board, Highway Capacity Manual, National Research Council, TRB, SR 209: Washington D.C., 2000.

[27] Akcelik, R., Chung, E. \& Besley, M., Roundabouts: Capacity and Performance Analysis, Research Report APR 321, ARRB, Transport Research Ltd.: Vermon South, Australia, 1998.

[28] National Association of Australian State Road Authorities (NAASRA), Guide to Traffic Engineering Practice-Intersections at Grade, Part 5, National Association of Australian State Road Authorities: Sydney, Australia, 1998.

[29] National Association of Australian State Road Authorities (NAASRA), Guide to Traffic Engineering Practice-Roundabouts, Part 6, AP-G11.6, National Association of Australian State Road Authorities: Sydney, Australia, 1998.

[30] Adams, M., Barker, D. \& Rye, T., Roundabouts. Unit 9, BE71008: Highway Planning and Design, 3rd edn. Napier University, School of the Built Environment: Scotland, UK, 2004.

[31] German Highway Capacity Manual, Handbook for Assessing Road Traffic Facilities (Forschungsgesellschaft fur das Strassen und Verkehrswesen, Handbuch fur die Bemessung von StraBenverkehrsanlagen, HBS), FGSV, no. 299, Verlag Gmbh: Koln, Germany, 2001.

[32] Brilon, W., Wu, N. \& Bondzio, L., Unsignalized intersections in Germany- A State of the Art, In Proceedings of the Third International Symposium on Intersections Without Traffic Signals, M. Kyte, ed. University of Idaho: Portland, Oregon, USA, 1997.

[33] Wu, N., Capacity of shared- short lanes at unsignalized intersections, In Proceedings of the Third International Symposium on Intersections Without Traffic Signals, M. Kyte, ed. University of Idaho: Portland, Oregon, USA, 1997.

[34] Lough, G., Panaroma critique des models Francais de capacite des carrefours giratoires, Proceedings of the Seminar Roundabouts 92, SETRA, BP 100, F 92223 Bagneux, Nantes, France, 1992.

[35] GIRABASE, Calculation of roundabout capacity, Available at www.certu.fr (accessed June 2008).

[36] Federal Highway Administration (FHWA), Roundabouts: An Information Guide, FHWA- RD00-067, US Department of Transport: Virginia, USA, 2000.

[37] Wardrop, J.G., The traffic capacity of weaving sections of roundabouts, Proceedings of the First International Conference on Operational research, English Universities Press: London, UK, 1957.

[38] Kadiyalli, L.R., Traffic Engineering and Transport Planning, Khanna Publisher: New Delhi, India, 1999.

[39] Al-Madani, H.M.N., \& Saad, M., Analysis of roundabout capacity under high demand flows. WIT Transactions on the Built Environment, vol. 107, Proceedings Urban Transport XV Urban Transport and the Environment, ed. Brebbia, C. A., WIT press: UK, pp. 223-234, 2009. 
[40] Montomery, D.C. \& Runger, G.C., Applied Statistics and Probability for Engineers, 3rd edn, John Wiley, Denver: USA, 2003.

[41] Wu, N.A., Universal procedure for capacity determination at unsignalized (Priority-Controlled) intersections. Transportation Res B, 35(3), 2001. USA.

[42] Seiberlich, E.L., A Formulation to Evaluate Capacity and Delay of Multilane Roundabouts in the United States for Implementation into a Trend Forecasting Model, M.Sc. Thesis, The University of Wisconsin: Milwaukee, USA, 2001. 